\title{
Research on the Mechanism of Rock Burst Prediction by Drilling Cutting Method
}

\author{
Hu Shanchao ${ }^{1}$, Lu Aihong ${ }^{1,2}$, Li Ming ${ }^{2}$, Duan Tianzhu ${ }^{3}$, Chang Xiya ${ }^{1}$ \\ ${ }^{1}$ School of Mechanics and Civil Engineering, China University of Mining \& Technology, 221116Xuzhou, China \\ ${ }^{2}$ State Key Laboratory for Geomechanics and Deep Underground Engineering, China University of Mining \& \\ Technology, 221116, Xuzhou, China \\ ${ }^{3}$ China Coal Technology Engineering Group Chong Qing Research Institute, 400039, Chongqing, China \\ *Corresponding Author: Hu Shanchao School of Mechanics and Civil Engineering, China University of \\ Mining \& Technology, 221116Xuzhou, China
}

\begin{abstract}
In order to clarify the relationship between drilling cutting quantity and stress state, a theoretical analysis was first conducted on the stress state of the surrounding rock; then, in the similar test of drilling cutting quantity measurement with the drilling cutting method, a drilling rig was used to drill the similar test piece in the tunnel environment simulated with a self-made machine; finally, the relationship between the drilling cutting quantity and confining stress was obtained. Through the analysis of the result, the following conclusions were obtained. With the increase of confining pressure, the drilling cutting quantity of different stages increased with the drilling distance and reached the maximum in the $35 \mathrm{~cm}-40 \mathrm{~cm}$ stage; then it decreased compared with that of the $35 \mathrm{~cm}-40 \mathrm{~cm}$ stage; the total drilling cutting quantity increased with the confining pressure and its increase tendency was more obvious than the theoretical value, and the test value of the total drilling cutting quantity was greater than the theoretical value under the same confining pressure; the distance between the pipe sticking position and the starting point of drilling decreased with the increase of confining pressure. Thus, it indicated an obvious dynamic effect and a high probability of rock burst.
\end{abstract}

Keywords: drilling cutting quantity; rock burst; theoretical analysis; similar test; pipe sticking

\section{INTRODUCTION}

Rock burst is one of the major disasters in coal mining. In the process of coal mining, the elastic energy accumulated in the coal and rock mass around coal mine tunnel and coal face under high stress may be suddenly released to cause coal and rock vibration and damage, resulting in casualties, support and equipment damage, collapse of partial tunnel, etc. Therefore, it is an important research direction in rock burst control and prevention to predict and forecast rock burst by effective means.

At present, a lot of research has been done on the methods of rock burst prediction and prevention both at home and abroad, for example, electromagnetic method, numerical simulation method, drilling cutting method, etc. Nie Baisheng et al. ${ }^{[1]}$ studied the rule of electromagnetic radiation of coal and rock mass when it was damaged and deformed by load. Yang Yong et al. ${ }^{[2]}$ judged whether the mechanical strength of rock mass reached the critical value based on electromagnetic radiation monitored in tunnels. Dou Linming et al. ${ }^{[3-6]}$ predicted coal and rock burst using the electromagnetic radiation technology and found that the higher the stress on coal and rock mass is, the more severe the deformation and fracture are, the stronger the electromagnetic radiation signals will be. Zhang Ji et al. ${ }^{[7]}$ determined the critical conditions of rock burst by observing the electromagnetic radiation parameters of coal and rock mass. Mou Zonglong et al. ${ }^{[8]}$ proposed the technical measures of removing the rock burst risk using roof blasting and determined the blasting parameters based on the numerical simulation. He Ye et al. ${ }^{[9-10]}$ analyzed the risk of rock burst in isolated coal face with electromagnetic radiation and adopted distress blasting for the isolated coal face according to the burst hazard index. Qu Xiaocheng et al. ${ }^{[11]}$ established the relationship between drilling cutting quantity, abutment pressure and borehole stress through analysis and numerical calculation based on the site monitoring data of Jining No. 3 Coal Mine, and on this basis, developed a rock burst real-time monitoring and warning system. Lu Zhenyu et al. ${ }^{[12]}$ connected the drilling cutting data obtained during tunneling using interpolation method to obtain the drilling cutting data of the whole tunnel; and 
then provided the rock burst risk levels of different sections of the tunnel according to the relationship between drilling cutting quantity, surrounding rock stress and rock burst. Zhang Xiaochun et al. ${ }^{[13]}$ simulated the process and phenomenon of rock burst with similar materials and coal materials and revealed the mechanism of rib-spalling rock burst due to sudden failure in the local coal wall.

However, both the numerical simulation method and electromagnetic method have certain limitations. For one thing, the numerical simulation method can be used to predict rock burst to some extent, but many factors influencing rock stress in actual situation are ignored; for another, the complicated underground water and electromagnetic environment in some wells seriously affect the result of electromagnetic radiation monitoring method, causing a big error in the result compared with the actual situation. Furthermore, the measurement of rock burst with drilling cutting method is mostly to evaluate the risk level of rock burst on site, with no drilling cutting quantity and rock burst relationship given most of the time. Therefore, the mathematical relationship between drilling cutting quantity and rock burst is still one of the major research directions at present.

In this paper, the relationship between drilling cutting quantity and the stress of surrounding rock is explored with similar materials and self-made equipment on the basis of theoretical derivation and analysis together with a comprehensive consideration of the stress state of rock mass in the underground environment. The result is of great significance for the prediction and prevention of rock burst.

\section{Analysis of The Drilling CutTing Quantity and Stress State RelationshiP}

In order to study the relationship between drilling cutting quantity and the stress state of rock mass in the tunnel, the mechanical model of the rock mass subject to stress during drilling was first established, as shown in Fig. 1. When the drilling rig drills the rock mass, elastic zone and plastic zone will occur around the borehole due to stress and mechanical disturbance around the drill bit. Suppose horizontal stress is $P_{1}$ and vertical stress is $P_{2}$. If the radius $r$ of the drill bit is a and the radius $R$ of mechanical disturbance equals to $\mathrm{b}$, then the area with an radius greater than $\mathrm{b}$ is the elastic zone, and the area with an radius of a-b is the plastic zone.

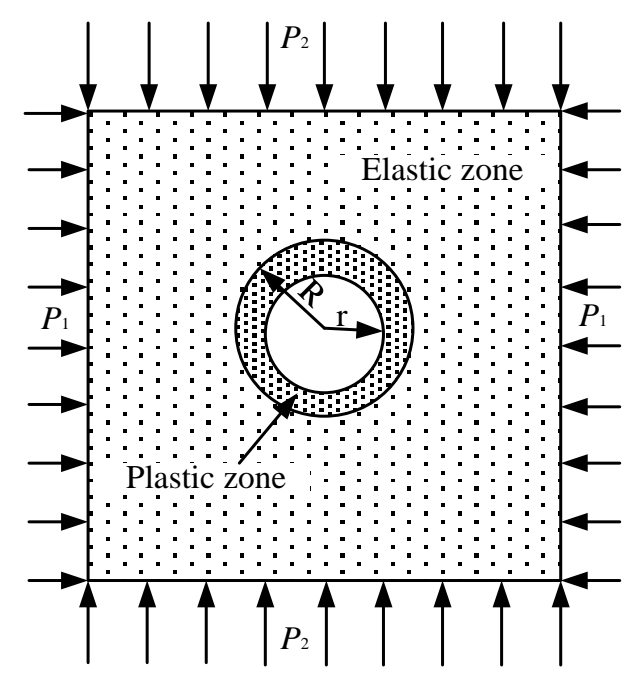

Fig1. The mechanical model of rock mass when horizontal stress equals to vertical stress

Through the established mechanical model of rock mass subject to stress in both directions combined with the mechanics of elasticity, it can be deduced that the horizontal and vertical stresses are respectively:

$$
\begin{aligned}
& \sigma_{r}=\frac{p_{1}+p_{2}}{2}\left(1-\frac{a^{2}}{r^{2}}\right)+\frac{p_{1}-p_{2}}{2}\left(1-\frac{a^{2}}{r^{2}}\right)\left(1-3 \frac{a^{2}}{r^{2}}\right) \cos 2 \alpha \\
& \sigma_{\alpha}=\frac{p_{1}+p_{2}}{2}\left(1+\frac{a^{2}}{r^{2}}\right)-\frac{p_{1}-p_{2}}{2}\left(1+3 \frac{a^{4}}{r^{4}}\right) \cos 2 \alpha
\end{aligned}
$$


Wherein, $\sigma_{\mathrm{r}}$ is the radial normal stress of rock mass; $P_{1}$ and $P_{2}$ are respectively the horizontal and vertical stresses on the rock model; $a$ is the diameter of the hole inside the rock mass. In the elastic zone, the rock mass conforms to Hooke's Law and its constitutive equation is:

$\sigma=E \varepsilon$

Wherein, $\sigma$ is elastic strength; $E$ is the elastic modulus of the rock model; $\varepsilon$ is the elastic strain of the rock model.

In the plastic zone, the rock mass applies to index relationship model and its constitutive equation is:

$$
\sigma_{p}=\sigma_{c}\left(\frac{\varepsilon}{\varepsilon_{c}}\right)^{m}
$$

Wherein, $\sigma_{\mathrm{p}}$ is the plastic strength of rock; $\sigma_{\mathrm{c}}$ is the uniaxial compressive strength of the rock model; $\varepsilon_{\mathrm{c}}$ is the uniaxial compressive strain of the rock model; and $m$ is the plastic softening coefficient.

The zone surrounding the borehole, namely the fringe zone, keeps balance under the common effect of the radial stress $\sigma_{r}$ and the tangential normal stress $\sigma_{\alpha}$, and thus the balance equation is obtained:

$$
\frac{d \sigma_{r}}{d r}+\frac{\sigma_{r}-\sigma_{\alpha}}{r}=0
$$

(5)

The yield condition is:

$\sigma_{\alpha}=k \sigma_{r}+\sigma_{c}, k=\frac{1+\sin \varphi}{1-\sin \varphi}$

Wherein, $\varphi$ is the internal friction angle of the rock model, with the value of $30^{\circ}$.

When drilling radius is a, the boundary condition of rock mass is $\sigma_{\mathrm{r}}=0$ and the stresses in both elastic zone and plastic zone are continuous. When the horizontal stress $P_{1}$ equals to the vertical stress $P_{2}$, i.e. $P_{1}=P_{2}=P$, the maximum radius of plastic zone is:

$$
R=b=a\left\{1+\frac{(2 m+k-1)\left(2 p-\sigma_{c}\right)}{\sigma_{c}^{1-m}\left[\sigma_{c}+(k-1) p\right]^{m}(k+1)}\right\}^{\frac{1}{2 m+k-1}}
$$

After the radius $R$ of the plastic zone is calculated, we can find the radial displacement of the inner wall of borehole on the basis of the condition that the size of plastic zone is unchanged. Since the elastic zone has very small displacement, we further get the boundary displacement of borehole fringe (from the condition that the size of plastic zone is unchanged) and the boundary displacement of elastic zone without considering the dilatation effect:

$$
\begin{aligned}
& u_{b}=\frac{1+\mu}{2 E} b\left[\left(\sigma_{c}+\frac{k-1}{k+1}\left(2 p-\sigma_{c}\right)\right]\right. \\
& u_{a}=\frac{b u_{b}}{a}
\end{aligned}
$$

Wherein, $u_{\mathrm{b}}$ is the boundary displacement of borehole zone; $u_{\mathrm{a}}$ is the boundary displacement of elastic zone; $\mu$ is the Poisson's ratio of rock model.

Considering the dilatation effect of the plastic zone and that the calculation model of dilatation effect is not yet mature, the mean dilatation coefficient $n(1 \leq n \leq 1.2)$ is used to calculate radial displacement $u_{\mathrm{a}}{ }^{\prime}$ of the inner wall of the borehole under the dilatation effect, as follows:

$u_{a}^{\prime}=\frac{b u_{b}}{a}+\frac{n-1}{2 a}\left(b^{2}-a^{2}\right)$

The total drilling cutting quantity during the drilling of rock mass include two parts. One is the drilling cutting quantity generated from the solid part of borehole, and the other is that generated in 
the plastic zone. Let the mass of drilling cuttings generated from an arbitrary unit length of the solid part of a borehole be $M_{1}$, then

$$
M_{1}=\rho \pi a^{2}
$$

Wherein, $\rho$ is rock mass density.

Let the mass of drilling cuttings generated from an arbitrary unit length of borehole due to boundary displacement and dilatation effect be $M_{2}$, then:

$$
M_{2}=2 \rho \pi a u_{a}^{\prime}=2 \rho \pi a\left(\frac{b u_{b}}{a}+\frac{n-1}{2 a}\left(b^{2}-a^{2}\right)\right)
$$

We can get from Equations (11) and (12) that the total mass of drilling cuttings generated from a unit length of borehole is $M$ :

$$
\begin{aligned}
& M=\rho\left(\pi a^{2}+2 \pi a u_{a}^{\prime}\right) \\
& =\rho\left(\pi a^{2}+2 \pi b u_{b}\right)+\rho \pi(n-1)\left(b^{2}-a^{2}\right) \\
& =\rho \pi\left[a^{2}+(n-1)\left(b^{2}-a^{2}\right)\right]+\frac{\rho \pi b^{2}(1+\mu)}{E}\left[\left(\sigma_{c}+\frac{k-1}{k+1}\left(2 p-\sigma_{c}\right)\right]\right. \\
& =\rho \pi\left[a^{2}+(n-1)\left(b^{2}-a^{2}\right)\right]+\frac{\rho \pi(1+\mu) a^{2}}{E}\left[\left(\sigma_{c}+\frac{k-1}{k+1}\left(2 p-\sigma_{c}\right)\right]\left\{1+\frac{(2 m+k-1)\left(2 p-\sigma_{c}\right)}{\sigma_{c}^{1-m}\left[\sigma_{c}+(k-1) p\right]^{m}(k+1)}\right\}^{\frac{2}{2 m+k-1}}\right.
\end{aligned}
$$

In this paper, the rock mass is an ideal elastoplastic material. Let $m$ be 0 and $n$ be 1 , then the total mass of drilling cuttings $M$ in Equation (13) can be simplified as follows:

$$
M=\rho \pi a^{2}+\frac{\rho \pi a^{2}(1+\mu)}{E}\left[\sigma_{c}+\frac{k-1}{k+1}\left(2 p-\sigma_{c}\right)\right]\left[1+\frac{(k-1)\left(2 p-\sigma_{c}\right)}{\sigma_{c}(k+1)}\right]^{\frac{2}{k-1}}
$$

\section{Test Piece Fabrication And Test Method}

\subsection{Test Piece Fabrication}

In this test, the materials for test piece fabrication are cement (32.5R), fine sand and water. The mixing ratio of cement, fine sand and water is shown in Table 1. In the fabrication, firstly, cement, fine sand and water of the correct ratio were put into a mixer for mixing for 3-5 minutes; secondly, the mold with the well mixed mortar was put on a vibration table to shake it until slurry appeared on the

\begin{tabular}{|c|c|c|c|c|c|c|c|c|}
\hline \multirow{2}{*}{$\begin{array}{c}\text { Test } \\
\text { piece } \\
\text { No. }\end{array}$} & \multicolumn{2}{|c|}{ Density/Kg. $\mathrm{m}^{-3}$} & \multicolumn{2}{|c|}{$\begin{array}{c}\text { Elastic modulus } \\
\mathrm{E} / \mathrm{GPa}\end{array}$} & \multicolumn{2}{|c|}{ Poisson's ratio $/ \mu$} & \multicolumn{2}{|c|}{$\begin{array}{l}\text { Compressive } \\
\text { strength/MPa }\end{array}$} \\
\hline & $\begin{array}{l}\text { Single } \\
\text { test piece }\end{array}$ & $\begin{array}{c}\text { Arithmetic } \\
\text { mean }\end{array}$ & $\begin{array}{c}\text { Single } \\
\text { test } \\
\text { piece }\end{array}$ & $\begin{array}{c}\text { Arithmetic } \\
\text { mean }\end{array}$ & $\begin{array}{c}\text { Single } \\
\text { test } \\
\text { piece }\end{array}$ & $\begin{array}{c}\text { Arithmetic } \\
\text { mean }\end{array}$ & $\begin{array}{c}\text { Single } \\
\text { test } \\
\text { piece }\end{array}$ & $\begin{array}{c}\text { Arithmetic } \\
\text { mean }\end{array}$ \\
\hline 1 & $1.76 \mathrm{e}-3$ & \multirow{5}{*}{$1.88 \mathrm{e}-3$} & 0.42 & \multirow[t]{5}{*}{0.42} & 0.29 & \multirow[t]{5}{*}{0.30} & 3.02 & \multirow[t]{5}{*}{3.32} \\
\hline 2 & $1.87 \mathrm{e}-3$ & & 0.45 & & 0.35 & & 3.50 & \\
\hline 3 & $1.91 \mathrm{e}-3$ & & 0.40 & & 0.26 & & 3.22 & \\
\hline 4 & $1.92 \mathrm{e}-3$ & & 0.39 & & 0.28 & & 3.35 & \\
\hline 5 & $1.96 \mathrm{e}-3$ & & 0.42 & & 0.32 & & 3.48 & \\
\hline
\end{tabular}
surface; finally, the test piece were let stand for $24 \mathrm{~h}$ and then demoulded and allowed to cure for 28 days. Basic physical and mechanical properties test was performed on the fabricated test piece, and the test results were shown in Table 2.

Table1. Mass ratio of the materials for test piece

\begin{tabular}{|c|c|c|c|}
\hline Materials & Fine sand & Cement & Water \\
\hline Ratio & 6.3 & 1 & 1.5 \\
\hline
\end{tabular}

Table2. Physical and mechanical parameters of the test piece

\subsection{Test Equipment}

The test equipment includes a bi-directional compression test system and a drill rig. The former is 
used to simulate the stress environment of the test piece, and the latter is for drilling the test piece to obtain drilling cuttings.

\section{(a) Compression test system}

The compression test system includes a hydraulic power system, a fixed loading system and display devices. The hydraulic power system includes hydraulic motor, hydraulic oil, oil pipes and pipe connector; the motor uses $220 \mathrm{~V} \mathrm{AC}$ and has a maximum power of $1.5 \mathrm{~kW}$. The fixed loading device includes a frame, a hydraulic cylinder and a pressure plates, etc.; the size of both pressure plates is $20 \mathrm{~cm} \times 49 \mathrm{~cm}$. The urethane rubber plates are used for applying uniform pressure on the test piece; the two horizontal plates are $1.2 \mathrm{~cm} \times 20 \mathrm{~cm} \times 50 \mathrm{~cm}$, and the two vertical ones are $1.2 \mathrm{~cm} \times 23 \mathrm{~cm} \times 50 \mathrm{~cm}$. The display devices include a pressure gauge connected with the hydraulic power system and another connected with the hydraulic cylinder. The reading of the former indicates the output hydraulic strength, and the latter indicates the vertical and horizontal pressures.

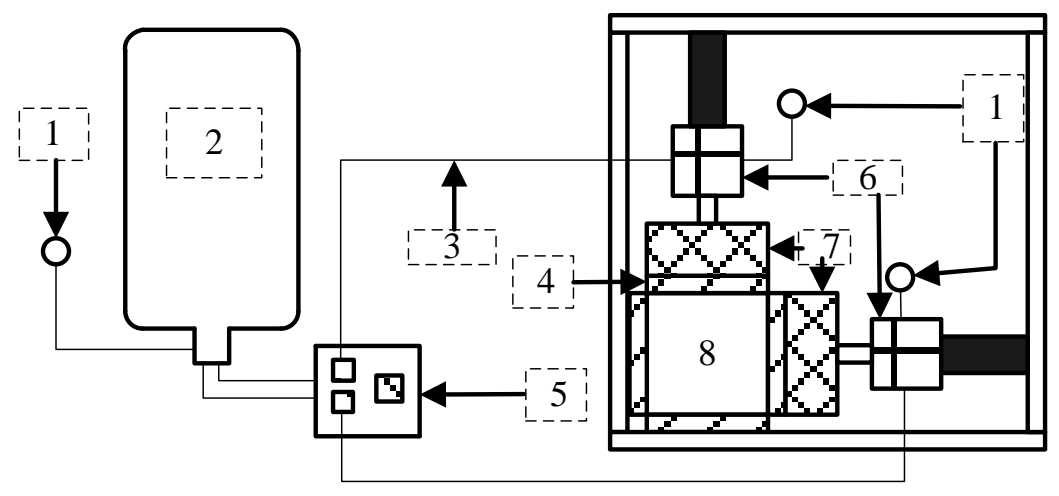

Fig2. Bi-directional compression test system

Legend: 1.Pressure gauge, 2.Hydraulic power plant, 3.Tubing, 4. Rubber Board, 5. Control valve, 6. Hydraulic cylinder, 7.Platen, 8.Model

(b) Drilling rig

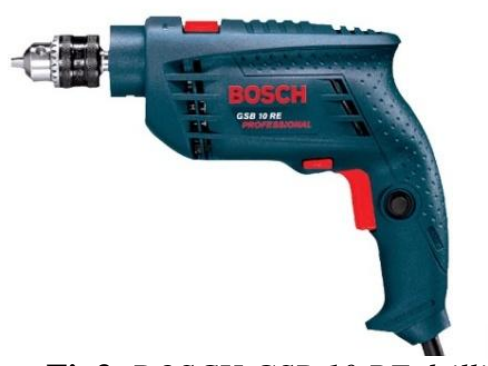

Fig3. BOSCH GSB 10 RE drilling

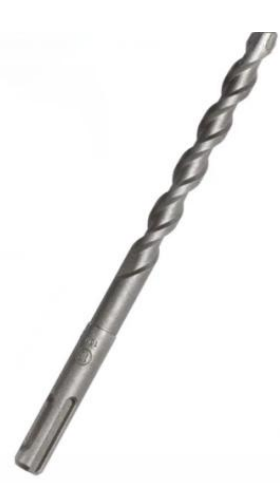

Fig4. Twist drill

The drilling rig used in this test is shown in Fig. 3, with the model number of BOSCH GSB 10 RE. The major technical parameters are $220 \mathrm{~V}$ AC, max output power of $800 \mathrm{~W}$, max zero-load speed of $900 \mathrm{rpm}$, and the optimal drilling range of $8-16 \mathrm{~mm}$. The twist drill used in this test is shown in Fig. 4, with a diameter of $13 \mathrm{~mm}$.

\subsection{Test Plan}

The test was carried out in seven batches, in each of which the vertical and horizontal pressures were equal. The pressures in the seven batches were 0.6, 0.7, 0.8, 0.9, 1.0, 1.2 and 1.4 MPa respectively. In the test, firstly, the test piece was put on the fixed table with rubber plates around the test piece; secondly, the reading of the pressure gauge of the hydraulic power device was adjusted to be the test value and the control valve was opened; finally, after the reading of the pressure gauge became stable, the electric drill was started to allow it drill into the test piece in the center at a uniform speed until the drilling length reached $45 \mathrm{~cm}$; during the drilling, the mass of drilling cuttings was recorded every $5 \mathrm{~cm}$ at the length of $5 \mathrm{~cm}, 10 \mathrm{~cm}, 15 \mathrm{~cm}, 20 \mathrm{~cm}, 25 \mathrm{~cm}, 30 \mathrm{~cm}, 35 \mathrm{~cm}, 40 \mathrm{~cm}$ and $45 \mathrm{~cm}$, and the pipe sticking positions were also recorded. 


\section{TEST RESULTS AND ANALYSIS}

\subsection{Relationship Between Confining Pressure and Drilling Cutting Quantity}

The drilling cuttings collected were weighed with a high-sensitivity electronic scale to obtain the data of each stage under different confining pressures, as shown in Table 3.

Table3. Drilling cutting quantities of each stage under different confining pressures

\begin{tabular}{|l|l|l|l|l|l|l|l|l|l|}
\hline \multirow{2}{*}{$\begin{array}{l}\text { Confining } \\
\text { pressure/MPa }\end{array}$} & \multicolumn{2}{|l|}{ Drilling cutting quantity/g } \\
\cline { 2 - 10 } & $\begin{array}{l}0-5 \\
\mathrm{~cm}\end{array}$ & $\begin{array}{l}5-10 \\
\mathrm{~cm}\end{array}$ & $\begin{array}{l}10-15 \\
\mathrm{~cm}\end{array}$ & $\begin{array}{l}15-20 \\
\mathrm{~cm}\end{array}$ & $\begin{array}{l}20-25 \\
\mathrm{~cm}\end{array}$ & $\begin{array}{l}25-30 \\
\mathrm{~cm}\end{array}$ & $\begin{array}{l}30-35 \\
\mathrm{~cm}\end{array}$ & $\begin{array}{l}35-40 \\
\mathrm{~cm}\end{array}$ & $\begin{array}{l}40-45 \\
\mathrm{~cm}\end{array}$ \\
\hline 0.6 & 15.92 & 11.64 & 11.79 & 11.52 & 12.01 & 12.09 & 13.30 & 14.01 & 13.20 \\
\hline 0.7 & 17.10 & 11.52 & 11.88 & 12.09 & 12.18 & 12.20 & 13.58 & 15.10 & 13.60 \\
\hline 0.8 & 19.53 & 11.67 & 11.81 & 11.79 & 12.07 & 12.14 & 13.67 & 15.21 & 13.75 \\
\hline 0.9 & 17.13 & 11.51 & 12.01 & 12.18 & 12.02 & 12.21 & 13.74 & 15.42 & 13.88 \\
\hline 1.0 & 16.68 & 11.76 & 11.97 & 12.20 & 12.28 & 12.29 & 13.68 & 15.63 & 13.92 \\
\hline 1.2 & 16.01 & 12.05 & 11.77 & 12.24 & 12.35 & 12.37 & 13.82 & 15.83 & 13.99 \\
\hline 1.4 & 15.29 & 12.07 & 12.08 & 12.35 & 12.47 & 12.60 & 13.97 & 15.94 & 14.10 \\
\hline
\end{tabular}

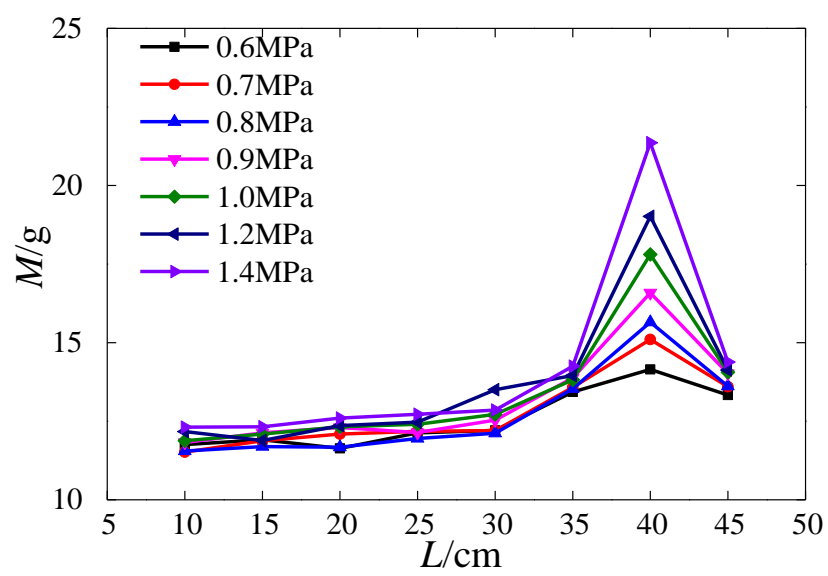

Fig5. Relationship between drilling cutting quantity in different stages and confining pressure

Fig. 5 shows the drilling cutting quantity - confining pressure curve. As the drill bit disturbance has great influence in the beginning stage, the drilling cutting quantity if the $0-5 \mathrm{~cm}$ stage is not included in the figure. As can be seen from Fig. 5, the changes of drilling cutting quantity of different stages with the confining pressure had both similarities and difference. In terms of similarities, the drilling cutting quantities of different stages under seven different confining pressures roughly had the same trend, namely, rising in the $0-35 \mathrm{~cm}$ stage, falling in the $40 \mathrm{~cm}-45 \mathrm{~cm}$ stage, with almost the same quantity with the $30 \mathrm{~cm}-35 \mathrm{~cm}$ stage; in terms of differences, confining pressure changes had different effect on the drilling cutting quantities of different stages, which was the most obvious in the $35 \mathrm{~cm}$ $40 \mathrm{~cm}$ stage. In this stage, the greater the confining pressure was, the larger the increasing range of drilling cutting quantity was compared with the previous stage.

\subsection{Relationship Between the Theoretical Value and Test Value of the Total Drilling Cutting Quantity}

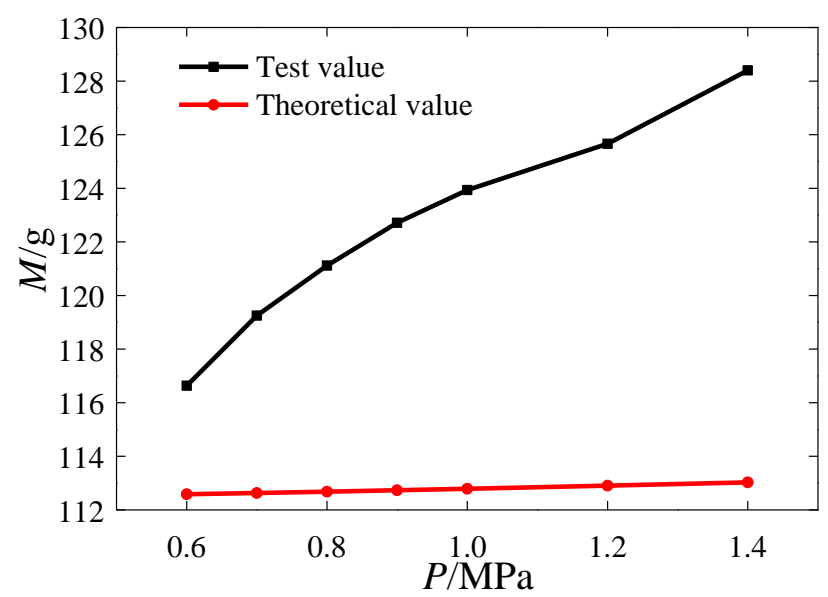

Fig6. Relationship between the theoretical value and test value of the total drilling cutting quantity 
Fig. 6 shows the relationship between the theoretical value and test value of the total drilling cutting quantity. It can be seen from Fig. 6 that the theoretical value and test value of the total drilling cutting quantity were roughly the same and both increased with the confining pressure. However, they also had some differences. The test values under each confining pressure were greater than the theoretical values; the test value $(10.9 \%)$ was greater than the theoretical value $(0.4 \%)$ in terms of the increase of total drilling cutting quantity when the confining pressure increased from 0.6 MPa to 1.4 MPa. This was caused by the error of theoretical value of the dilation zone size compared with the actual size in the test process, and the higher the confining pressure was, the greater the error would be.

\subsection{Relationship between pipe sticking position and confining pressure}

Pipe sticking, as a kind of dynamic effect, is an intuitive index of impact tendency. Recording the dynamic effect during drilling can help more accurately judge the risk position.

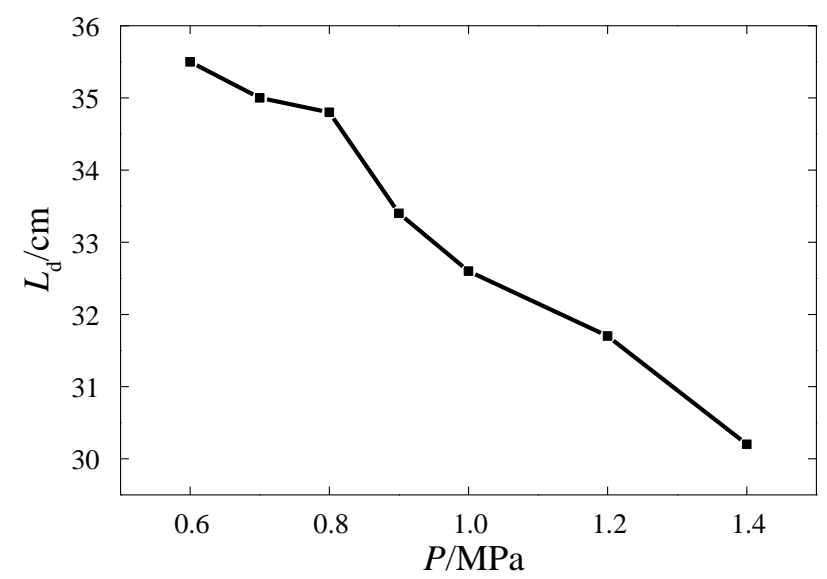

Fig7. Relationship between pipe sticking position and confining pressure

Fig. 7 shows the relationship between pipe sticking position and confining pressure. As can be seen from Fig. 7, the distance between the pipe sticking position and the starting point of drilling became shorter with the increase of confining pressure. Fitting is carried out according to the relationship between pipe sticking position and confining pressure shown in Fig. 7 and Equation (15) is obtained. Equation (15) shows a linear decrease of pipe sticking position with the increase of confining pressure, namely, the higher the confining pressure is, the earlier the dynamic effect comes.

$$
\left\{\begin{array}{c}
L_{d}=-6.8204 p+39.745 \\
R^{2}=0.98
\end{array}\right.
$$

\section{Conclusions}

In this paper, the relationship between drilling cutting quantity and confining pressure is studied on the basis of theoretical derivation and experimental research, and the conclusions of the test result analysis are as follows:

(1) The drilling cutting quantity of different stages under different confining pressures almost changed in the same trend along with the drilling process. The drilling cutting quantity increased with the drilling distance and reached the maximum in the $35 \mathrm{~cm}-40 \mathrm{~cm}$ stage; from the $30 \mathrm{~cm}-35 \mathrm{~cm}$ stage to the $35 \mathrm{~cm}-40 \mathrm{~cm}$ stage, the drilling cutting quantity had the largest increase under the confining pressure of 1.4 $\mathrm{MPa}$ and the smallest under the confining pressure of 0.6 MPa.

(2) Both the theoretical value and test value of the total drilling cutting quantity increased with the confining pressure, but the latter was greater than the former under different confining pressures because the actual size of the dilation zone was greater than the theoretical value.

(3) The pipe sticking position showed a linear decrease with the increase of confining pressure. The higher the confining pressure was, the closer it was to the drilling starting point.

\section{REFERENCES}

[1] NIE Baisheng, HE Xueqiu, WANG Enyuan, et al. Forecasting rock burst with the electromagnetic emission method in coalmine[J]. Journal of Taiyuan University of Technology, 2000, 31(6): 609-611. 
[2] YANG Yong, PAN Yishan, LI Guozhen. Research on monitoring dangerous area of rock bursting with portable electromagnetic emission instrument [J]. Coal Mining Technology, 2007, 12(2): 62-64.

[3] Du L M, He X Q, Wang E Y. Electromagnetic emission technique of monitoring rock burst and its application [J]. Journal of China Coal Society, 2004, 29(4): 396-399.

[4] Du L M, He X Q. Rock burst control theory and technology [M]. China University of Mining Press, 2001.

[5] Du L M,Cao Q W, He X Q. Electromagnetic Radiation Monitoring Technique for the Rock Burst[J]. Mine Pressure and Roof Management. 2002, 19(4): 89-91.

[6] Du L M, He X Q, Wang E Y, et al. Experimental research on the electromagnetic emission of rock \& coal burst failure [J]. Zeszyty Naukowe Politeehniki Slaskiej, 2000(246): 371-376.

[7] Zhang Ji, Xiao ShuangShuang. Prediction of rock burst by electromagnetic radiation [J].Shanxi Coking Coal Science\& Technology, 2010(7): 32-34.

[8] Mu Zong-long, Dou Lin-ming, Zhang Guang-wen, et al. Study of prevention methods of rock burst disaster caused by hard rock roof $[\mathrm{J}]$. Journal of China University ofMining \& Technology, 2006, 35(6):737-741.

[9] He Ye, Cai Qing-xiang, Dou Lin-ming, et al. Hazards of rock burst in island coal face and its control in coal mine jining No.2 [J]. Rock and Soil Mechanics, 2003, 24(supp): 593-596.

[10] He Ye, Peng Fei, Hu Xue-jun, et al. Monitoring and Control of Roek Burst in Island Coving Coal Face [J]. Journal of China University ofMining \& Technology, 2004, 33(5): 569-572.

[11] Qu Xiaocheng, Jiang Fuxing, Yu Zhenxing, et al. Rock burst monitoring and precaution technology based on equivalent drilling research and its applications [J]. Chinese Journal of Rock Mechanics and Engineering, 2011, 30(11): 2346-2351.

[12] Lu Zhenyu, Dou linming, Xu Xuefeng, et al. New discovery on drilling cuttings method to detect surrounding rock stress of mine roadway and predict mine pressure bumping dangers [J]. Coal Engineering, 2011(1): 72-74.

[13] Zhang Xiaochun, Yang Tingqing, Miao Xiexing. The simulation test of rockburst in coal mines [J]. Chinese Journal of Geotechnical Engineering, 1999, 21(1): 66-70.

Citation: Hu Shanchao et al. (2017). Research on the Mechanism of Rock Burst Prediction by Drilling Cutting Method, International Journal of Mining Science (IJMS), 3(4), pp.81-88, DOI: http://dx.doi.org/ 10.20431/2454-9460.0304007.

Copyright: () $2017 \mathrm{Hu}$ Shanchao et al. This is an open-access article distributed under the terms of the Creative Commons Attribution License, which permits unrestricted use, distribution, and reproduction in any medium, provided the original author and source are credited 